\section{Edycasáa

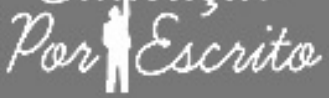

ARTIGO

\section{Editor}

Alexandre Anselmo Guilherme PUCRS, RS, Brasil

\section{Editor Assistente}

Cibele Cheron

PUCRS, RS, Brasil

\section{Editores Associados}

Bruno Antonio Picoli

Universidade Federal da Fronteira Sul, Chapecó, SC, Brasil

Pricila Kohls dos Santos Universidade Católica de Brasília, Brasília, DF, Brasil

Renato de Oliveira Brito

Universidade Católica de Brasilia, Brasilia, DF, Brasil

Elisa Ustarroz

PUCRS, Porto Alegre, RS, Brasil

\section{ISSN 2179-8435}

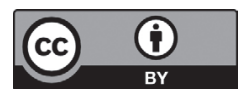

Este artigo está licenciado sob forma de uma licença Creative Commons Atribuiçăo 4.0 Internacional, que permite uso irrestrito, distribuição e reprodução em qualquer meio, desce corretamente citada

\title{
O professor de Educação Física em formação: o desafio teoria-prática na construção da profissionalidade
}

\author{
The Physical Education teacher in formation: the theory-practice challenge \\ in the construction of professionality
}

\author{
José Augusto Ayres Florentino 1 \\ Lucas Souza Santos ${ }^{2}$ \\ ${ }^{1}$ Pontifícia Universidade Católica do Rio Grande do Sul (PUCRS), Porto Alegre, RS, Brasil. \\ ${ }^{2}$ Federação de Estabelecimentos de Ensino Superior, Novo Hamburgo, RS, Brasil.
}

\section{RESUMO}

O presente estudo é fruto de uma pesquisa que tem como objeto a formação inicial de professores, investigando a constituição do campo dos saberes do estudante, professor em formação. Para tanto, partiu-se da seguinte questão: De que forma os estudantes, professores de Educação física em formação, estão constituindo seus saberes, principalmente, no que diz respeito a articulação entre teoria e prática, incluindo as tensões entre o campo da formação (Faculdade) e o campo profissional (Espaço Escolar) que configuram o exercício da docência na Educação Física, e de que forma esses saberes contribuem para a construção da sua profissionalidade? Este estudo é de abordagem qualitativa, descritiva, de cunho exploratório. Do resultado das análises pode-se destacar que os estudantes, professores de Educação Física em formação, consideram-se responsáveis pelo aprendizado de seus alunos, servindo de referência para os m'esmos; a respeito da inserção desde cedo à prática docente, os estudantes consideram como um campo de conhecimento importante para a formação e construção da sua profissionalidade, como um conjunto de comportamentos, conhecimentos, atitudes e valores que constituem a especificidade de ser professor.

Palavras-chave: Formação inicial de professores. Profissionalidade. Saberes docentes. Teoria-prática. Prática pedagógica.

\section{ABSTRACT}

The present study is the result of a research that has as its object the initial formation of teachers, investigating the constitution of the field of knowledge of the student, teacher in formation. Therefore, the following question was asked: How are students, teachers of Physical Education in formation, are constituting their knowledge, especially regarding the articulation theory and practice, including the tensions between the field of formation 
(Faculty)? and the professional field (School Space) that configure the exercise of teaching in Physical Education, and how this knowledge contributes to the construction of their professionality? This is a qualitative, descriptive, exploratory approach. From the analysis results it can be highlighted that the students, teachers of Physical Education in formation, consider themselves responsible for the learning of their students, serving as reference for them; Regarding the early insertion into teaching practice, students consider it as an important field of knowledge for the formation and construction of their professionality, as a set of behaviors, knowledge, attitudes and values that constitute the specificity of being a teacher.

Keywords: Initial teacher education. Professionality Teaching knowledge. Practical theory. Pedagogical practice.

\section{Introdução}

$\mathrm{O}$ grupo "Formação de Professores, Cultura Corporal e Práticas Pedagógicas", criado em 2014, aprofunda em pesquisas sobre a formação inicial e continuada de professores e está ligado ao curso de Educação Física da Faculdade Cenecista de Osório/RS. Neste início de caminhada estamos colaborando, em nossos estudos, com a pesquisa: Os saberes do professor de Educação Física em formação: o desafio teoria-prática e as tensões do campo da formação e do campo profissional na construção da profissionalidade, em movimentos iniciais, tem como objeto de estudo a formação inicial de professores, investigando a constituição do campo dos saberes do estudante, professor em formação, para compreender a articulação teoria-prática e as tensões do campo da formação (Faculdade) e do campo profissional (Espaço Escolar).

De acordo com Fernandes e Cunha (2013) o discurso oficial sobre a formação de professores vem apontando a necessidade de currículos organizados em processos que privilegiem a tematização dos conhecimentos escolarizados, dos saberes da experiência, da iniciação científica, da inserção na prática no campo profissional desde cedo.

Essas novas diretrizes curriculares implicam os estudantes em uma inserção no campo profissional desde o início do curso e trazem uma nova dimensão, qual seja, a prática como componente curricular. A inserção do professor em formação desde o início do curso rompe com uma visão de que a teoria antecede à prática e esta, a prática, reduz-se à aplicação de teorias, compreensão de conhecimento e de ciência por vezes ainda presente em nossos currículos e em nossas concepções (FERNANDES; FERNANDES, 2005).

No que diz respeito às contribuições para o avanço do conhecimento em estudos nesta área, podemos afirmar que as exigências da profissionalização e de uma construção da profissionalidade reabriram o debate e provocaram 
a necessidade de repensar a formação inicial. Esta, por sua vez, requer a exigência de uma epistemologia da prática, construída em bases sólidas pela reflexão teórica a partir da prática; necessitando de um tempo de maturação para uma inserção orientada no campo profissional, o que demanda um currículo que permita a prática como componente curricular (FERNANDES; FERNANDES, 2005; FERNANDES; CUNHA, 2013). Precisamos fortalecer o sentimento de pertença dos estudantes, enfatizando o significado da sua presença nas atividades a serem realizadas pelos professores em formação no percurso do curso, neste caso o de Educação Física.

Para tanto, partimos dos pressupostos acima descritos, para perguntar: De que forma os estudantes, professores de Educação física em formação, estão constituindo seus saberes, principalmente, no que diz respeito a articulação teoria e prática, incluindo as tensões entre o campo da formação (Faculdade) e o campo profissional (Espaço Escolar) que configuram o exercício da docência na Educação Física, e de que forma estes saberes contribuem para a construção da sua profissionalidade?

O objetivo geral da pesquisa foi compreender como vem sendo constituído o campo de saberes dos estudantes, incluindo as tensões entre o campo da formação e o campo profissional, e de que forma estes saberes contribuem para a construção da sua profissionalidade.

\section{Formação inicial de professores e as tensões do campo da formação e do campo profissional}

Ao falar em formação, formação inicial de professores, acreditamos ser importante trazer algumas discussões conceituais iniciais como forma de situar o campo. Campo este, plural, mutável, que nunca tem fim, uma vez que "não nos formamos em um único lugar, por meio de uma única instituição", nossa formação se dá a partir da "informação visual, textual, comportamental, pelo dito e pelo não dito. Daí a formação ser eminentemente um processo socializador e, como tal, inclui considerar o outro como elemento constitutivo dessa formação" (PINTO, 2010, p. 112).

Compreende-se que o professor age a partir de saberes que são plurais e construídos por diferentes fontes. Constrói seus saberes com raiz em múltiplas influências de formação, em cotejamento com o contexto cultural e institucional em que atua (TARDIF, 2008). Desta maneira, a construção da profissionalidade do professor requer, desde a formação inicial, a constante reflexão do que se faz, como se faz e como deveria ser feito. Como diz Sacristán (2010, p. 248, tradução nossa): "a profissionalidade está ligada à dinâmica pessoal e vital que é única para cada indivíduo, só cabe falar de uma profissionalidade docente como uma agregação de particularidades". Os docentes em exercício constroem novos conhecimentos, ideias e práticas, pois é a partir daquilo que já possuem e sabem que continuam desenvolvendo a sua profissionalidade. 
Assim, ao falar em profissionalidade, tem-se a ideia de docência como processo de constituição da identidade profissional, desenvolvido pelos professores ao longo de sua trajetória de vida e profissional, nos diferentes espaços de socialização, desde a escolarização, à formação profissional e à organização escolar, local em que todos nós, professores, exercemos e aprendemos a profissão (CONTRERAS DOMINGO, 2010; SACRISTÁN, 1999). Em relação a este processo, estudos (NÓVOA, 1992; PIMENTA, 2000; TARDIF, 2008) sobre a formação de professores vêm apontando a prática docente como lugar relevante de formação e produção de saberes, evidenciando a relação entre formação e exercício da profissão, em que o professor mobiliza os saberes profissionais, construídos e reconstruídos conforme a necessidade de utilização dos mesmos.

Pensamos que a prática é essencial para a formação do professor, tendo em vista que não há como se formar por completo se em algum momento da vida acadêmica o indivíduo não ter oportunidade de vivenciar a prática. Sendo assim, a formação deve ser vivenciada em parceria com a prática docente, para que o professor possa superar os desafios de tornar-se um profissional reflexivo e crítico. A profissão de professor precisa combinar sistematicamente elementos teóricos com situações práticas reais. Para Tardif (2008), a relação que os professores e os saberes devem ter não pode estar apenas vinculada à transmissão de conhecimentos, pois, na prática, há uma integração de vários outros saberes que se constituem do saber docente, considerado como um saber plural, sendo estes saberes oriundos da formação profissional, disciplinar, curricular e os da experiência.

\section{Trajetória metodológica}

Após submissão à Plataforma Brasil e aprovação pelo Comitê de Ética em Pesquisa (CEP) do Centro Universitário Cenecista de Osório/RS - UNICNEC, protocolo CAAE no 36024014.2.0000.5591, deu-se início à pesquisa que correspondeu a um estudo exploratório (GIL, 2008) inserido em uma abordagem qualitativa, descritiva. Participaram da pesquisa vinte estudantes, professores de Educação Física em formação, do curso de Licenciatura de uma Faculdade do litoral norte do Rio Grande do Sul. Foi critério de inclusão que os estudantes tivessem vivenciado pelo menos um dos Estágios Supervisionados oferecidos pelo curso de Educação Física (Estágio em Educação Infantil; Anos Iniciais do Fundamental; Anos Finais do Fundamental; Ensino Médio), ou, então que estivessem participando do Programa Institucional de Bolsas de Iniciação à Docência (PIBID) da Coordenação de Aperfeiçoamento de Pessoal de Nível Superior (Capes). O número de participantes foi determinado a partir de estudos realizados por Minayo et al. (1994), para os quais a pesquisa qualitativa não deve basear-se no critério numérico para garantir sua representatividade e, sim, no questionamento que o pesquisador deve ter em mente, ou seja, quais indivíduos sociais têm uma vinculação mais significativa para o problema a ser investigado? O instrumento utilizado para a coleta de dados foi a entrevista 
semiestruturada (MINAYO et al., 1994). Os estudantes de Educação Física que participaram da pesquisa assinaram o Termo de Consentimento Livre e Esclarecido, que foi lido, explicado pelo pesquisador, e assinado pelos participantes e o próprio pesquisador responsável, permanecendo uma cópia com o estudante e outra com o pesquisador. Para a análise dos dados fizemos uso da Análise Textual Discursiva (MORAES, 2003). A fim de manter o sigilo de identidades, os estudantes participantes desta pesquisa foram identificados através de codigos (como EFI 1; EFI 2). Os depoimentos foram concedidos aos pesquisadores nas dependências da UNICNEC, na cidade Osório, RS, Brasil, entre setembro de 2015 e março de 2016.

\section{Com a palavra os estudantes... relatos indiciários}

A análise dos dados nos permitiu organizar os relatos em duas categorias (temas), as quais destacamos a seguir.

\section{As concepções de professores narradas pelos estudantes, professores de Educação Física em formação}

Consideramos importante em um contexto educacional que futuro professor em formação tenha bem presente que o seu papel é o de propiciar ao aluno situações de autoconstrução. "Eu espero nas minhas aulas desenvolver atividades que tornem eles cidadãos mais conscientes, mais responsáveis [...]" (EFI 4, informação verbal). Isso significa que ele é responsável pelo aprendizado, que o futuro professor é mediador dessa autoconstrução e referência para o seu aluno (NETTO et al., 2012). Tal fato fica evidente na fala a seguir:

“[...] professor é um profissional que vai ajudar no desenvolvimento da cidadania das pessoas [...] tem que desenvolver outros aspectos da formação das crianças, o convívio social, o aspecto atitudinal, os valores que muitas vezes as crianças não têm isso em casa [...] então na minha opinião o professor ele é um dos profissionais que deveriam ser mais valorizados no Brasil, e não só, mas no mundo inteiro, porque eu acho que ele tem essa capacidade de transformar a realidade do contexto onde ele trabalha." (EFI 1, informação verbal)

A prática pedagógica do professor é construída de relações de boa convivência e de uma profissionalidade ética, de qualidade e criativa; ela desperta no aluno relações de carinho e de idealização. O aluno lança um olhar sob o professor, como um sujeito transformador, que por meio de seus ensinamentos conseguirá trilhar o caminho e construir sua identidade. Nesse sentido, o professor compartilha mais do que conhecimentos, compartilha ideias e também o coração (GADOTTI, 2007). Tornando-se referência na formação dos seus alunos, além dos conteúdos específicos, o 
professor ensina a sua noção de mundo, os seus referenciais, suas crenças, seus valores, seus conceitos, seus ideais, seus pressupostos, ou seja, o seu Eu.

Corroborando com o pensamento de Gadotti (2007), os estudantes têm a compreensão do que vem a ser o professor e seu comprometimento para com seus alunos: "[...] minha ideia de professor, vai muito além da sala de aula, do conteúdo específico ou até mesmo de uma prática aplicada, acho que ser professor é conhecer o aluno, a necessidade dele [...]" (EFI 2, informação verbal). Conhecendo estas necessidades, "[...] a diferença vai ser na formação pessoal deles [...] incentivar eles a prática de esporte [...] ter condições de vida melhor, mais saúde, eu quero ser esse professor que cuida do aluno" (EFI 8, informação verbal). Da mesma forma, "[...] segue por aí a questão de valores que hoje em dia está bem complicado [...]" (EFI 6, informação verbal), pois há "pais que acham que é dever da escola tu passar os valores para as crianças, tem umas que não tem estrutura nenhuma, então acho que ser professor tem essa parte do ensinamento" (EFI 10, informação verbal). Soma-se a isto, nos dias atuais, onde [...] as crianças ficam cada vez mais isoladas eu acho, dentro de suas casas, na tecnologia também, essa vivência humana, essa troca de experiências, essa conversa, sobre o cotidiano do dia-a-dia, acho que é importante a gente como educador físico, ter um espaço maior para estar trabalhando isso, um trabalho do corpo né, um trabalho mais completo (EFI 11, informação verbal). Partindo destes relatos:

"O professor que faz a diferença é aquele que vai até o aluno, é difícil tu aguardar do aluno uma coisa que: 'espero que o aluno venha até mim'. Não! é muito complicado, então acho que o professor tem que ir até o aluno [...] tem que procurar saber do teu aluno o que tem por trás daquele problema psicológico do teu aluno, coisas que refletem nas aulas, aquilo que ele demonstra, então eu acho que o professor em si tem que fazer a diferença, não resolver o problema do aluno, mas auxiliar da melhor forma possível, dentro do seu alcance.” (EFI 2, informação verbal)

Toda profissão é uma construção social e, como tal, deve atender a algumas exigências de um dado contexto histórico e social - como se apontou nas falas anteriores -, bem como traz uma concepção do futuro profissional sobre o que constitui sua profissão, o que é ser professor (PINTO, 2010). Esse fator está relacionado a um processo de construção da identidade que tem início desde cedo nas primeiras experiências profissionais no espaço escolar (estágios, programas de iniciação à docência etc.). Nesta construção, para Nóvoa (1997), fica evidente que as dimensões pessoais e profissionais não podem ser separadas e que uma influenciará fortemente a outra, por consequência, a atuação desse profissional, suas reflexões sobre seu planejamento, o olhar de compreensão sobre os alunos, e suas vivências em aulas são "tão (ou mais) importante[s] do que as técnicas que aplica ou os conhecimentos que transmite; 
os professores constroem a sua identidade por referência a saberes (práticos e teóricos), mas também por adesão a um conjunto de valores" (NÓVOA, 1997, p.33).

A identidade profissional docente "se apresenta, pois, como uma dimensão comum a todos os docentes [e ao próprio professor em formação], e como uma dimensão específica, em parte individual e em parte ligada aos diversos contextos de trabalho" (GARCÍA, 2010, p. 19). Para García trata-se de uma "construção individual referida à história do docente e às suas características sociais, mas também de uma construção coletiva derivada do contexto no qual o docente se desenvolve" (GARCÍA, 2010, p. 19, grifo nosso). Nesse contexto, a figura do professor como pessoa e profissional são inseparáveis quando se trata de uma profissão construída sobre fundamentos éticos, impregnado de valores e de intencionalidade (FLORENTINO, 2013).

Ao longo das narrativas dos estudantes, professores de Educação Física em formação, surgiram posicionamentos que deram vida ao entendimento do que vem a ser um professor que faz a diferença: "aquele que vai até o aluno, ser criativo, diálogo, interação, valorização, o mais atualizado possível, ouvir o aluno, ter conhecimento, educação, incentivador, compromisso com o aluno, dedicação, atento às mudanças, crescimento, trabalho com as diferenças, humano, esse professor que cuida do aluno, ser um professor diferente".

Percebemos também que a preocupação em fazer uma Educação Física diferente faz parte do pensamento de muitos dos estudantes, em uma tentativa de "desconstruir a imagem atual, essa imagem do 'largobol', e dar um outro sentido" (EFI 13, informação verbal) à profissão. Senão vejamos:

"A gente vê naturalmente em nosso país a questão do esporte, principalmente o futebol, e o aluno muitas vezes passa por todo o ensino sem experimentar coisas diferentes, eu acho que essa experimentação é indispensável para a criança e para o adolescente, por que tem que mostrar isso para ele, como pode acrescentar na vida dele posterior a escola, essas vivências. Ele vai ter toda uma vida pós-escola, ele vai ter diversas experiências... e isso ele vai estar vivenciando dentro da escola, essa bagagem que ele vai carregar para vida dele, então até para gente sair daquele tradicional do esporte, do jogar bola só... é importante você estar passando isso para o aluno e para ele entender que ali é um espaço para ele vivenciar coisas, em um ambiente controlado, com pessoas qualificadas que estudaram para isso, para que ele possa vivenciar isso, vivenciar coisas diferentes, aprender, para que ele leve essa bagagem para o resto da vida dele [...].” (EFI 11, informação verbal).

Podemos perceber que o respeito pela pessoa do aluno é recorrente nas falas dos estudantes e no próprio entendimento que eles possuem sobre o professor que faz uma diferença significativa e o que seria para eles uma boa aula de Educação Física. Também temos que ressaltar uma preocupação quanto ao papel da Educação Física na 
vida dessas crianças e jovens. Fica claro que além dos aspectos pedagógicos (metodologias adotadas, planejamentos, conteúdos etc.), os aspectos pessoais (as atitudes do professor em formação como pessoa, os valores transmitidos, os atributos comportamentais e emocionais) também são importantes, tendo em vista as contingências nas relações entre professores e alunos na prática pedagógica.

Percebemos nas narrativas uma preocupação não apenas com a aprendizagem, mas também, com o desenvolvimento e o aprimoramento das relações afetivas com seus alunos. Mostraram-se pessoas preocupadas com a sua formação profissional, com o tipo de professor que almejam ser; tornam-se exigentes e essa exigência está presente no processo educativo para que contemplem as necessidades e as potencialidades dos alunos.

Portanto, ser professor que faz a diferença vai exigir sensibilidade e ampliação de consciência por parte do futuro docente que agora precisará ter uma visão crítica e responsável de seu agir. É necessário que o professor tenha consciência de que a sua maneira de ser, suas crenças e intenções, se revelam no que é ensinado aos alunos, pois para Nóvoa a inseparabilidade da pessoa e do profissional é justificada quando afirma que "ser professor obriga a opções constantes que cruzam nossa maneira de ser com nossa maneira de ensinar, e que desvendam na nossa maneira de ensinar a nossa maneira de ser" (NÓVOA, 1997).

Partindo das reflexões de Tardif (2008), vê-se que os professores em formação constroem sua profissionalidade e/ou seu ofício de ensinar a partir de diversas experiências, dentro e fora da escola, não há profissionalidade produzida diretamente por eles. Essas experiências "provêm de lugares sociais anteriores à carreira propriamente dita ou situados fora do trabalho cotidiano. Por exemplo, alguns provêm da família do professor, da escola que o formou e de sua cultura pessoal; outros procedem das universidades [...]" (TARDIF, 2008, p. 64, grifo nosso).

Portanto, temos que a identidade do professor se define em um equilíbrio entre as características pessoais e profissionais, do que se conclui que suas ações traduzem a plenitude de sua pessoa; em outras palavras, muito das ações dos estudantes, professores de Educação Física em formação, como pessoa e professor, podem ser traduzidas pelos saberes (experiências vividas) e os conhecimentos adquiridos ao longo de sua formação no contexto familiar, escolar e social (FLORENTINO, 2013, grifo nosso).

\section{Ação e reflexão no agir pedagógico: tensóes entre o campo da formação e o campo profissional}

A docência em todas as suas dimensões representa um desafio e exige um conjunto de conhecimentos para o seu planejamento e exercício. Neste sentido, damos início às análises destacando as dificuldades encontradas pelos estudantes, professores de Educação Física em formação, ao planejar as suas aulas nas escolas: 
"[...] eu me preocupo com isso, que eles gostem da aula e fiquem ali vidrados, então as vezes não faço uma atividade que seja mais complexa por medo deles dispersarem muito e eu não conseguir dar conta de chamar de volta, ou eles "ah! Professora, não gostei", acho que isso seria muito frustrante para mim." (EFI 14 , informação verbal)

"[...] é encontrar a atividade que vai agradar a grande maioria dos alunos, porque cada um, cada ser é único e a gente não vai conseguir agradar a todo mundo, a maior dificuldade que eu tenho assim é que às vezes eu demoro muito para fazer, é porque eu quero tentar atingir o maior número de alunos naquela atividade, que a maioria deles se interessem, daí eu fico pensando como é o fulano, o que ele gosta de fazer [...].” (EFI 8, informação verbal).

Analisando os depoimentos acima, podemos perceber certa preocupação dos estudantes quanto a sua aula e a forma como irão organizá-la no seu agir pedagógico, sendo que "duas angústas" se repetem frequentemente nas falas: 1) a incerteza: "A grande dificuldade é que eu nunca sei se vai dar certo, a gente planeja um plano que para mim às vezes está perfeito, maravilhoso, não tem como dar errado, chega lá na hora e aí" (EFI 10, informação verbal) e 2) a participação de todos: "[...] fazer um planejamento para que eu englobe todos os meus alunos, faça com que eles se divirtam aprendendo com a minha matéria, com a minha disciplina e ainda sim fiquem motivados" (EFI 15, informação verbal). Veiga (2008) ressalta que o objetivo principal da organização da aula é possibilitar ao professor um trabalho docente mais significativo e comprometido com a qualidade das atividades propostas. Para a autora a organização da prática representa "o produto de um movimento processual de reflexão e decisão, de comprometimento e criticidade" (VEIGA, 2008, p. 274).

Com base nos depoimentos dos professores em formação, podemos fazer uma aproximação com o que Huberman (2007) apontou em seu estudo, isto é, que o início da docência é um período nevrálgico na carreira dos professores (e dos próprios professores em formação). Assim como Huberman, pensamos que o primeiro contato com a prática, essa chamada sobrevivência, é o confronto entre o que se aprende na academia e a realidade encontrada nas escolas, um período de intensa aprendizagem, de tensões entre teoria e prática, de dificuldades com os alunos, com o pouco material disponível nas escolas: “[...] as dificuldades que eu encontro [...] é a questão de pouco material, pouca teoria para eu me basear [...] e também eu fico preocupada... será que os alunos vão gostar, se os alunos não gostarem o que que eu faço [...]" (EFI 4, informação verbal).

Podemos inferir que o êxito no alcance dos objetivos e interesses dos alunos vai depender da forma como o professor ou o futuro professor enfrenta as incertezas e a complexidade do mundo da prática. A aula é constituída de um sistema complexo de significados, de relações e de intercâmbios que ocorrem em um contexto social 
que define as demandas da aprendizagem. E o professor tem de ser o mediador dessa ação (VASCONCELOS, 1995).

As discussões em torno da educação se encaminham para um ponto convergente - o professor precisa ser um educador e não mais um instrutor, transmissor conteudista de conhecimento (ARRUDA; PORTAL, 2012). Além disso, as respostas dos estudantes nos permitem inferir que a educação necessita cada vez mais de professores preparados para enfrentar as incertezas do seu agir pedagógico. Frente a esta realidade, a prática pedagógica se apresenta bastante complexa, e as preocupações manifestadas em suas falas perpassam justamente as constantes e ininterruptas transformações pelas quais o ensino está passando.

Outro ponto a destacar é a necessidade desse educador assumir uma posição não só de ensinante, mas também de aprendente, pois vivemos um tempo que nos desafia a ensinar e a aprender ao mesmo tempo. Dentro desta perspectiva, à medida que se vai construindo a prática pedagógica (seja nos estágios, seja nos programas de iniciação à docência), novos saberes, novas experiências vão a ela se incorporando e se transformando em trabalho docente, ou seja, em experiência profissional.

Fato é que, ao longo da nossa profissão "praticamos teorias e não podemos perder a oportunidade de teorizarmos nossa prática. É nessa reflexão que se dá o movimento fundamental à reforma de nossos saberes e fazeres e, por conseguinte, de nossas ações e práticas" (ARRUDA; PORTAL, 2012, p. 205). Nesse trabalho docente, mediado pelo agir pedagógico, que se constrói e reconstrói com novos conhecimentos e novas experiências (TARDIF, 2008). Em uma análise inicial, fica evidente que os estudantes, professores de Educação Física em formação - seja nos estágios ou em programas como o PIBID - constroem seus saberes a partir das experiências na Faculdade e, principalmente, na Educação Básica, com professores que foram referências para enfrentar as contingências da prática escolar.

Neste contexto, a prática pedagógica, que é o agir docente no espaço escolar, depende não só dos conhecimentos formais, adquiridos nos cursos de formação, mas também depende das ações e reflexões que os estudantes, professores de Educação Física em formação, fazem do seu agir docente, das relações com seus alunos, de seus pares e da própria escola. É neste sentido que Tardif (2008) aponta os saberes escolares, os saberes pedagógicos e os saberes docentes e experienciais como fenômenos que se misturam na atividade diária do professor - e do próprio professor em formação.

Para Veiga (2008) temos que estar dispostos a modificar as rotinas de nosso agir pedagógico, de nosso processo educativo e de nosso procedimento didático:

"Toda aula eu acho que aprendo um pouco com aquilo que eu fiz, com aquilo que eu fiz os alunos fazerem também... porque eu acho que é a partir dessas reflexões que eu vou poder transformar a minha prática 
numa aula que atraia as crianças que se envolvam de uma maneira espontânea, porque eu acho que é a partir da reflexão que a gente vai melhorar nosso trabalho, eu acho que se a gente não reflete sobre aquilo que faz, tu não tem um retorno e consequentemente tu não sabe se tu está bem ou mal, se aquilo que tu fez é bom ou ruim [...] mas eu acho que é importante a partir do meu ponto de vista perceber o que eu fiz, o que deu certo, o que deu errado e a partir desses acertos e erros adaptar o planejamento e executar ele de uma maneira que seja agradável para os alunos e satisfatória para mim;” (EFI 1, informação verbal).

Posto isto, parece-nos que o primeiro passo foi dado pelos próprios estudantes, professores de Educação Física em formação, no que tange a construção de sua profissionalidade, ao refletirem sobre a prática pedagógica, sobre a organização de suas aulas, questionando seu papel e a sua responsabilidade no momento de planejar.

Dessa forma, o estágio e o próprio PIBID buscam em sua concepção a preparação do futuro profissional para o trabalho docente, sendo um campo de conhecimento importante para a formação dos estudantes, professores de Educação Física em formação. De acordo com Pimenta e Lima (2010, p. 55), atividades como o estágio - e o PIBID - possibilitam o "conhecimento, a análise e a reflexão do trabalho docente, das ações docentes, nas instituições, a fim de compreendê-las em sua historicidade, identificar seus resultados, os impasses que apresenta, as dificuldades".

Neste contexto, a articulação teoria-prática é um processo definidor da qualidade da formação inicial do professor, como sujeito autônomo, na construção de sua profissionalidade. Sendo assim, temos que a profissionalidade depende, entre muitos fatores, de como o professor compreende e analisa a sua prática educativa, como articula os saberes da docência no seu ato de ensinar; como reflete a ação frente às contingências. O processo progressivo e contínuo, baseiase no desenvolvimento de competências e da identidade profissional; inicia-se na profissionalização e prolonga-se ao longo de toda a carreira, sendo, por isso, um processo que permite aos professores apropriarem-se das práticas, da cultura e dos valores da profissão (TARDIF; FAUCHER, 2010). Em relação aos cursos de formação, Freire (1996), ressalta a importância destes no sentido de prepararem os professores como profissionais e como seres situados histórico-culturalmente, orientados a construir uma prática docente crítica, cada vez mais rica e significativa, a partir dos saberes que dizem respeito a ações pedagógicas coerentes com uma opção político-pedagógica emancipadora.

Dessa forma, pensamos que a inserção na prática no campo profissional desde cedo, a participação em programas de iniciação à docência, possibilitam aos alunos refletir e compreender as contingências da prática pedagógica, principalmente no que se refere a articulação teoria e prática e as tensões do campo da formação e do campo profissional no que se refere ao preparo para sua inserção profissional. A este respeito, quando perguntados sobre como veem a ida à prática logo no início de sua formação acadêmica muitos dos estudantes relataram em suas falas a importância de enfrentar cada vez mais cedo esta realidade: 
"Acho interessante, apesar de ser um choque de realidades, é um choque de realidade interessante, por que mais cedo ou mais tarde nós somos obrigados a enfrentar os alunos, obrigados a enfrentar a prática, e quanto mais cedo melhor, para irmos nos acostumando com esse ambiente e se adequando, para que daí sim a gente consiga saber em que ambiente nós vamos estar, e como planejar nossas aulas." (EFI 17, informação verbal).

"No início tu erras muito, tu pecas muito, te equivocas, em muitas situações tu acabas te equivocando, por que tu esperas uma coisa diferente, achando que aquela atividade é mega legal e a atividade não é legal, daí assim... tu já sentes, chega numa turma e bah! Aquela atividade que dá certo aqui, não dá ali, daí com o passar do tempo a gente vai se sentindo e do início da faculdade até aqui muita coisa mudou, por que são quatro anos, é bastante tempo [...].” (EFI 2, informação verbal)

Segundo Tardif (2008, p. 51), os futuros professores, quando "inseridos nas instituições de ensino, podem vivenciar uma distância entre os saberes experienciais e os saberes adquiridos na formação, como um choque da 'dura realidade"". A partir da prática pedagógica, o docente deve apresentar o domínio de comportamentos abrangendo as atitudes e posturas, como a disciplina, a pontualidade, a coerência, a clareza, o diálogo e o respeito às pessoas dos educandos; comportamentos, estes, que lhes permitirão a construção da sua profissionalidade.

\section{Considerações finais}

À guisa de conclusão podemos perceber que os estudantes, professores de Educação Física em formação, consideram-se responsáveis pelo aprendizado de seus alunos, servindo de referência para os mesmos. Nas falas dos alunos pode ser observado a concepção de professor que está sendo formada, isto é, um profissional comprometido com o seu aluno, em uma tentativa de fazer a diferença, que seja um mediador do conhecimento, que faça o seu aluno ser o protagonista da sua própria ação.

No que se refere às tensões do campo da formação e do campo profissional os estudantes em sua maioria mostraram-se preocupados com a prática pedagógica, no enfrentamento das contingências, deixando transparecer certa angústia quanto ao seu futuro profissional. Esta angústia se revela no que Huberman (2007) chamou de período nevrálgico em que há um choque com a realidade, isto é, o confronto entre o que se aprendeu na teoria e a realidade (prática pedagógica) como se mostra verdadeiramente; um período marcado por tensões, angústias, erros e, também, acertos do seu agir.

A respeito da inserção desde cedo à prática, os estudantes consideram como um campo de conhecimento importante para a formação e construção da sua profissionalidade, uma vez que a profissionalidade é "a afirmação 
do que é específico na ação docente, isto é, o conjunto de comportamentos, conhecimentos, destrezas, atitudes e valores que constituem a especificidade de ser professor" (SACRISTÁN, 1999, p. 65, grifo nosso). Assim, temos observado que o sucesso no seu agir não depende apenas dos saberes adquiridos no curso de formação, mas também da capacidade de cada estudante em refletir sobre suas ações.

\section{Referências}

ARRUDA, Maria Patrício; PORTAL, Leda Lísia F. Saberes e fazeres docentes: o dilema da reforma do pensamento e da prática pedagógica do educador do século XXI. Revista Percursos, Florianópolis, v. 13, n. 1, jan./jun., 2012. Disponível em: http://www. periodicos.udesc.br/index.php/percursos/article/viewFile/2369/2075. Acesso em: 1 nov. 2012. https://doi.org/10.5965/

1984724617332016117

CONTRERAS DOMINGO, José. Ser y saber en la formación didáctica del profesorado. Revista Interuniversitaria de Formación del profesorado, Zaragoza, n. 68, v. 2, p. 61-81, ago. 2010. https://doi.org/10.6018/reifop.18.3.190271

FERNANDES, Cleoni Maria Barboza; FERNANDES, Sonia. As questões da prática pedagógica como componente curricular nas Licenciaturas. In: ANPED - 40 ANOS DA PÓS-GRADUAÇÃO EM EDUCAÇ̃̃O NO BRASIL, 2005, Caxambú. Anais [...]. Caxambú, p. 1-5, 2005.

FERNANDES, Cleoni Maria Barbosa; CUNHA, Maria Isabel. Formação de professores: tensão entre discursos, políticas, teorias e práticas. Revista Inter-Ação, Goiânia, v. 38, n. 1, p. 51-65, jan./abr. 2013. https://doi.org/10.5216/ia.v38i1.25127.

FLORENTINO, José Augusto Ayres. A formação continuada de professores no ensino técnico profissionalizante: a (re)construção da profissionalidade em tempos de paradigma emergente. 2013. 212 f. Tese (Doutorado em Educação) - Pontifícia Universidade Católica do Rio Grande do Sul, 2013. https://doi.org/10.5327/z2447-211520191900023

FREIRE, Paulo. Pedagogia da autonomia: saberes necessários à prática educativa. Rio de Janeiro: Editora Paz e Terra, 1996. p. 54. https://doi.org/10.18764/2446-6549.2019.10355

GADOTTI, Moacir. A escola e o professor: Paulo Freire e a paixão de ensinar. São Paulo: Publisher, 2007.

GARCÍA, Carlos Marcelo. O professor iniciante, a prática pedagógica e o sentido da experiência. Revista Brasileira de Pesquisa sobre Formação Docente, [s. l.], v. 3, n. 3, p. 11-49, ago./dez. 2010. Disponível em: http://formacaodocente.autenticaeditora.com.br. Acesso em: 16 nov. 2012. https://doi.org/10.31639/rbpfp.v9i17.155

GIL, Antônio Carlos. Como elaborar projetos. São Paulo: Atlas, 2008. 
HUBERMAN, Michaël. O ciclo de vida profissional dos professores. In: NÓVOA, António. Vidas de professores. Porto: Porto Editora, 2007. p. 31-62.

MINAYO, Maria Cecília de Souza et al. (org.). Pesquisa social: teoria, método e criatividade. Rio de Janeiro: Vozes,1994. p. 80.

MORAES, Roque. Uma tempestade de luz: a compreensão possibilitada pela análise textual discursiva. Ciência \& Educação, São Paulo, v. 9, n. 2, p. 191-211, 2003. https://doi.org/10.1590/s1516-73132003000200004

NÓVOA, António. Formação de professores e profissão docente. In: NÓVOA, António. Os professores e sua formação. Porto: Porto Editora, 1997. p. 15-33. https://doi.org/10.1590/2175-623684910

NÓVOA, António. Os professores e as histórias da sua vida. In: NÓVOA, António. Vidas de Professores. Porto: Porto Editora, 1992. p. 11-30.

NETTO, Carla et al. Cartas: um instrumento desvelador que faz a diferença no processo educacional. Revista Educação por Escrito, Porto Alegre, v. 3, n.1, jul. 2012. Disponível em: http://revistaseletronicas.pucrs.br/ojs/index.php/porescrito/article/ view/11025/8141. Acesso em: 12 set. 2012.

PIMENTA, Selma Garrido; LIMA, Maria Socorro Lucena. Estágio e docência. São Paulo: Cortez, 2010. https://doi.org/10.14572/ nuances.v3i3.50

PIMENTA, Selma. Garrido. Formação de professores: identidade e saberes da docência. In: PIMENTA, Selma Garrido (org.). Saberes pedagógicos e atividade docente. São Paulo: Cortez, 2000. p. 15-34.

PINTO, Maria das Graças Gonçalves. O lugar da prática pedagógica e dos saberes docentes na formação de professores. Acta Scientiarum Education, Maringá, v. 32, n. 1, p. 111-117, 2010. https://doi.org/10.4025/actascieduc.v32i1.9486

SACRISTÁN, J. Gimeno. La Carrera profesional para el profesorado. Revista Interuniversitaria de Formación del profesorado, Zaragoza, n. 68, v. 2, p. 243-260, ago. 2010.

SACRISTÁN, J. Gimeno. Consciência e ação sobre a prática como libertação profissional dos professores. In: NÓVOA, António. Profissão professor. Porto: Porto Editora, 1999. p. 63-92.

TARDIF, Jacques; FAUCHER, Caroline. Um conjunto de balizas para a avaliação da profissionalidade dos professores. In: ALVES, Maria; MACHADO, Eusébio (org.). O pólo de excelência: caminhos para a avaliação do desempenho docente. Porto: Areal Editores, 2010. p. 32-53. https://doi.org/10.31692/2358-9728.iicointerpdvl.2015.00136

TARDIF, Maurice. Saberes docentes e formação profissional. Petrópolis: Vozes, 2008. p. 325. 
VASCONCELOS, Celso dos S. Construção do conhecimento em sala de aula. São Paulo: Libertad, 1995.

VEIGA, Ilma Passos de Alencastro. Organização didática da aula: um projeto colaborativo de ação imediata. In: VEIGA, Ilma Passos de Alencastro. Gênese, dmensões, princípios e práticas. Campinas: Papirus, 2008. p. 267-298. https://doi.org/10.14393/ er-v23n1a2016-11

Recebido em: 8/12/2019.

Aprovado em: 20/12/2019.

Publicado em: 17/4/2020.

\section{Endereço para correspondencia:}

José Augusto Ayres Florentino

Rua Nestor José Nitschke, 60 - Guarujá

91771-021, Porto Alegre, RS, Brasil

\section{Autores:}

José Augusto Ayres Florentino

Doutor em Educação pela Pontifícia Universidade Católica do Rio Grande do Sul (PUCRS), Porto Alegre, RS, Brasil. Professor de Educação Física no Estado do Rio Grande do Sul, RS, Porto Alegre, Brasil.

Orcid: https://orcid.org/0000-0001-5643-5810

E-mail: jose.a.a.florentino@gmail.com

Lucas Souza Santos

Mestrando em Diversidade Cultural e Inclusão Social pela Federação de Estabelecimentos de Ensino Superior em Novo Hamburgo (FEEVALE), Novo

Hamburgo, RS, Brasil. Professor de Educação Física nas redes municipais de ensino de Canela e de Gramado, RS, Brasil.

Orcid: https://orcid.org/0000-0002-1023-8480

E-mail: lucasefi94@gmail.com

Endereço: Av. João Pessoa, 338, apto 302 - Vila Luiza

95680-000, Canela, RS, Brasil 